\title{
Safety of intravenously applied mistletoe extract - results from a phase I dose escalation study in patients with advanced cancer
}

\author{
Roman Huber ${ }^{1 *}$, Dietrich Schlodder ${ }^{2}$, Carola Effertz ${ }^{2}$, Sabine Rieger ${ }^{2}$ and Wilfried Tröger $^{3}$
}

\begin{abstract}
Background: Mistletoe extracts have anti-tumor properties and are approved for subcutaneous use in cancer patients. Data on Intravenous application are limited.

Methods: An aqueous extract from pine-mistletoe was used to investigate maximum tolerable dose (MTD) and safety of intravenous application. It was infused once weekly for 3 weeks in patients with advanced cancer. Any type of cancer was included; relevant exclusion criteria were concurrent chemo- or radiation therapy. The classical phase I 3 + 3 dose escalation scheme was followed. Predefined dose groups were 200, 400, 700, 1200 and 2000 mg. Maximum planned dose was 2000 mg. With the MTD three more patients should be treated for 9 weeks in order to evaluate intermediate term tolerability. Weekly during the treatment and 1 week later tolerability, clinical status, safety laboratory parameters and adverse events were documented.
\end{abstract}

Results: Twenty-one patients (3 in the dose groups 200, 400, 700 and 1200 mg, respectively, 9 in the dose group $2000 \mathrm{mg}$ ) were included. MTD was not reached. Because one dose-limiting toxicity (DLT), an allergic reaction, occurred during infusion of $2000 \mathrm{mg}$, three more patients had to be included in this dose group and tolerated it, as well as the three patients who received $2000 \mathrm{mg}$ for 9 weeks. Occasionally in the dose group $2000 \mathrm{mg}$ mild to moderate fever occurred.

Conclusion: Weekly infusions of $2000 \mathrm{mg}$ of the pine-mistletoe extract were tolerated and can be used in further studies but had a risk for allergic reactions and fever. German Clinical Trials Register (Trial registration number DRKS00005028).

Keywords: Viscum album, Intravenous, Cancer, Clinical trial, MTD, Side effects

\section{Background}

Viscum album is a species of mistletoe that occurs predominantly in central Europe, growing as a semiparasitic plant on various host trees. Extracts from Viscum album (VaE) have been used since decades in complementary cancer therapy, especially within the concept of anthroposophic medicine. They contain various substances with biologic activity (mistletoe lectins (ML), viscotoxins, polysaccharides, flavonoids, phenylpropanoids, triterpenoids and others) of which ML have

\footnotetext{
* Correspondence: roman.huber@uniklinik-freiburg.de

${ }^{1}$ Center for Complementary Medicine, University Medical Center Freiburg, Faculty of Medicine, University of Freiburg, Breisacher Str. 115B, 79106 Freiburg im Breisgau, Germany

Full list of author information is available at the end of the article
}

been found most interesting. Mistletoe extracts and ML have shown to possess distinct cytotoxic effects on a panel of 38 cancer cell lines with low $\mathrm{IC}_{50}$ values $(0.026 \mu \mathrm{g} / \mathrm{ml})$ for ML [1]. In addition to cytotoxicity, $\mathrm{VaE}$ and ML have shown immunomodulatory properties, which are mediated by an activation of dendritic cells [2]. After subcutaneous application in humans, VaE increased the number of T-cells, eosinophils and neutrophil granulocytes in comparison to placebo $[3,4]$ and there is some evidence from randomized, placebocontrolled clinical trials that quality of life of cancer patients during chemo- or radiation therapy is improved [5]. Therefore, subcutaneously applied standardized VaE are approved in Germany and other countries for supportive therapy in cancer patients irrespective of cancer 
type $[6,7]$. Because of local reactions at the site of injection, which are related to the amount of $\mathrm{ML}$ in $\mathrm{VaE}$ $[3,4]$, tolerability of doses with systemic anticancer activity is limited by this route of application; it causes relevant pain, nausea and fever [8]. Absorption of $\mathrm{ML}$ from the gastrointestinal tract has been shown in an in vitro model with M-cells [9], but overall absorption of ML after oral application in humans seems to be poor, because they interact with carbohydrate residues on epithelial cells $[10,11]$ and no studies in humans have been performed with orally applied VaE. Therefore, the intravenous route is interesting to apply cytotoxic concentrations of $\mathrm{ML}$, but so far data for this route of application are very limited. In an observational study off label VaE infusions have been regarded as safe but some patients reported fever or pruritus [12]. Single controlled studies reported prevention of immunosuppression related to chemotherapy [13] or operative stress [14, 15]. In a small RCT $(n=64)$ patients with colorectal cancer had prolonged survival with postoperative chemotherapy and i.v. VaE compared to chemotherapy alone [16]. The maximum tolerable dose of i.v $\mathrm{VaE}$ is unknown. Because of the promising in vitro cytotoxicity of $\mathrm{ML}$ and first reports about clinical effects and good safety of i.v VaE in cancer patients, we systematically wanted to investigate dose related safety and maximum tolerable dose of a $\mathrm{VaE}$ and performed a prospective phase I clinical trial.

\section{Methods}

\section{Study medication}

The mistletoe product Helixor ${ }^{\circledR}$ P (Helixor Heilmittel $\mathrm{GmbH}$, Rosenfeld; Germany) was used for the study. Helixor $^{\ominus} \mathrm{P}$ is registered in Germany since 1982 as an anthroposophic medicinal product for subcutaneous injection [17]. It is derived from mistletoes growing on pine trees. One ampoule of $2 \mathrm{ml}$ solution for injection contains the extract of $100 \mathrm{mg}$ of fresh mistletoe herb (drug to extract ratio is 1:20). Extracting agent is water for injection, sodium chloride (99.91:0.09). This $100 \mathrm{mg}$ extract contains about $1000 \mathrm{ng} / \mathrm{ml}$ ML-III. For intravenous infusion the respective dose was diluted with $250 \mathrm{ml}$ physiologic saline solution and infused in three hours' time. The rationale for using Helixor ${ }^{\bullet} \mathrm{P}$ was, that some beneficial clinical experiences have been reported with this extract $[18,19]$ and that it has a high content of ML.

\section{Study design}

The prospective, dose-escalating, phase I GCP study without control group was performed at the Center for Complementary Medicine, University Medical Center Freiburg, Germany. The classical phase I $3+3$ dose escalation scheme was followed. Predefined dose groups were $200,400,700,1200$ and $2000 \mathrm{mg}$. If three patients tolerated three infusions of the first dose $(200 \mathrm{mg})$ in weekly intervals, the next three patients received three infusions of the next dose $(400 \mathrm{mg})$ and so forth. Maximum planned dose was $2000 \mathrm{mg}$. If the maximum dose was tolerable three more patients should be treated weekly for 9 weeks in order to evaluate intermediate term safety. The choice of the starting dosage (2 ampoules of Helixor ${ }^{\oplus}$ P $100 \mathrm{mg} / 2 \mathrm{ml}$ ) is based on above mentioned clinical experiences, not showing any side effects below this dosage. The choice of the highest dosage (20 ampoules of Helixor ${ }^{\oplus} 100 \mathrm{mg} / 2 \mathrm{ml}$ ) is derived from the demand of limiting the endotoxin level in solutions for intravenous infusions to $5 \mathrm{IU}$ per $\mathrm{kg}$ body weight per hour. The internal specification for endotoxins is $\leq 24.0 \mathrm{IU} / \mathrm{ml}$ Helixor ${ }^{\oplus} \mathrm{P}$. Infusion of $2000 \mathrm{mg} \mathrm{Helixor}^{\oplus} \mathrm{P}$ in a patient of $60 \mathrm{~kg}$ body weight accordingly should take $3.2 \mathrm{~h}$. Based on experiences with i.v. mistletoe treatment, an increased rate of febrile reactions and allergic or pseudoallergic reactions has been expected [12].

\section{Objectives}

Primary objective was to determine the maximum tolerated dose (MTD) of i.v. Helixor ${ }^{\oplus}$ P. The MTD is based on the incidence of dose-limiting toxicities (DLTs). Secondary objectives were to investigate safety and tolerability of the different dosages and the clinical course of the patients.

\section{Study population}

Female and male patients $\geq 18$ years of age with a histological or cytological confirmed diagnosis of an advanced malignant disease in an interval without antineoplastic therapies with an ECOG: performance status 0-2 and sufficient bone marrow function, defined as leucocytes $\geq 3000 / \mathrm{mm}^{3}$, neutrophils $\geq 1500 / \mu \mathrm{l}$, and thrombocytes $\geq 100,000 / \mathrm{mm}^{3}$ in the peripheral blood were included. Exclusion criteria were severe concomitant diseases (e.g. cardiovascular, respiratory, autoimmune disease needing immunosuppressants, severe allergic illness), fever, hyperthyreoidism, known hypersensitivity to mistletoe products, preceding therapy with mistletoe products, creatinine level $>1.5 \mathrm{mg} / \mathrm{dl}$, bilirubine level $>3 \mathrm{x}$ upper limit of normal, aminotransferase levels $>3 \mathrm{x}$ upper limit of normal, planned or current therapy with surgery, radiotherapy or chemotherapy, known abuse of medicaments, alcohol or illegal drugs, pregnancy or breast feeding, participation in another clinical study and dependence in relation to the sponsor's or investigator's institutions. Informed consent was obtained of all patients before inclusion in the study.

\section{Quality assurance}

The study was conducted in accordance with the Declaration of Helsinki, with the International Conference on 
Harmonization (ICH) Good Clinical Practice Guidelines and the German drug law. It was approved by the German health authorities (BfArM), and registered in the European Union (EudraCTno, 2012-004189-16) and the German Clinical Trials Register Freiburg (Trial registration number DRKS00005028, date of registration May 8th, 2013). The positive vote of the responsible ethical committee (University of Freiburg, Germany) was obtained before onset of the study (EK 93/13). All study procedures followed the clinical study protocol and the Standard Operating Procedures (SOPs) of the sponsor, the data management, and the $\mathrm{CRO}$ which are based on the current regulatory and ethical requirements. In addition, a study-specific monitoring guideline, a data management plan, and a statistical analysis plan had been prepared. The conduct of the study was supervised by specifically trained clinical monitors.

The study personnel of the study site was instructed by the clinical monitor in the clinical study protocol, the study procedures, GCP, and administrative and regulatory procedures (e.g. reporting of serious adverse events) during a study initiation visit. After study initiation, the clinical monitor performed 15 monitoring visits.

\section{Adverse events (AEs), dose limiting toxicity (DLT) and maximum tolerable dose (MTD)}

Any untoward medical occurrence, irrespective of the relationship to the study medication or study procedure, were recorded as $\mathrm{AE}$ in the $\mathrm{CRF}$, assessed on its grade of severity, causality to the study medication, clinical consequences and outcome and classified as serious (SAE), suspected unexpected serious (SUSAR), if applicable. Dose limiting toxicity (DLT) was defined as a specific $\mathrm{AE} \geq$ grade 2. Grading of specific AEs expected during MI were

Grade 1: Transient rash, drug fever $\leq 39,8{ }^{\circ} \mathrm{C}$ for less than $24 \mathrm{~h}$

Grade 2: Urticaria, and/or asymptomatic bronchospasm, drug fever $>39,8^{\circ} \mathrm{C}$ or drug fever $>39.5{ }^{\circ} \mathrm{C}$ continuing more than $24 \mathrm{~h}$

Grade 3: Symptomatic bronchospasm, requiring parenteral medication(s), with or without urticaria; allergy-related edema/angioedema

Grade 4: Anaphylaxis

Also an unexpected increase of aminotransferase levels to $>3 \times$ baseline levels or any CTCAE $\geq$ grade III, if a causal relationship cannot be ruled out and happened between the 1st and one week after the last application was assessed as DLT. The MTD is defined as the highest dose applied within this study that provokes a DLT at a maximum probability, defined prior to study opening. In analogy to most MTD-finding studies and corresponding to the pretended toxicity threshold of the $3+3$ design, a DLT maximum probability of $33 \%$ was chosen for this trial [20].

\section{Safety and tolerability assessments}

Each patient received a complete physical examination at screening visit and at study exit. Weekly during the study, the patient was briefly examined (vital signs, weight, examination of areas of pre-existing problems, temperature). An electronic thermometer and a patient diary were given to the patients to measure body temperature at about 8:00 am 2:00 pm and 8:00 pm at home daily.

Weekly white and red blood cell count, bilirubin, creatinine, aspartate and alanine aminotransferase (AST, ALT), gamma glutamyl transferase ( $\gamma \mathrm{GT})$, alkaline phosphatase (AP), albumin, chloride, sodium, potassium, calcium, uric acid, and prothrombin time were checked.

Tolerability was rated by the patient in the patient diary at day 1 and day 2 after the infusion on a 5 -point scale: very good, good, moderate, bad, and very bad.

\section{Sample size, statistics and data management}

All data from the CRF were recorded into the $\mathrm{ACCESS}^{\oplus}$ database by input masks reflecting content and layout of the CRF forms. Independent double data entry with third party reconciliation was used; data were validated according to a validation plan. Medical coding used MedDRA for concurrent diseases and adverse events, and WHO-DD for therapies and concomitant medications. Sample size of this dose finding phase I study was planned according to three scenarios which showed that between a minimum of 6 and a maximum of 33 patients had to be included.

Three analysis populations (full analysis set (FAS), safety analysis set (SAS) of patients, who at least received one MI, and per protocol set (PPS) of subjects without major protocol violations) were defined and analysed separately. Missing data were not imputed. Primary analysis was descriptive, safety and tolerability were analysed with explorative statistics by the statistical program IBM SPSS Statistics Professional.

\section{Results}

From 93 patients who were screened for the study, 72 had to be excluded, mostly because chemotherapy was planned or because they had been pre-treated with mistletoe preparations. 21 patients with advanced or metastasized cancer were included. Table 1 shows the types of cancer and characteristics of the patients at baseline. Most patients were pre-treated with surgery, chemotherapy and radiotherapy. All patients were Caucasians and had no chemo- or radiation therapy during the study period. 3 patients each were treated with 200, 400, 700, 1200 and $2000 \mathrm{mg}$ Helixor $^{\circledR} \mathrm{P}$ for three weeks, 
Table 1 Patient characteristics

\begin{tabular}{|c|c|}
\hline Characteristics & \\
\hline Age in years (median and range) & $64(42-74)$ \\
\hline Gender (number of male and female patients) & $17 / 4$ \\
\hline \multicolumn{2}{|l|}{ ECOG-performance status (number of patients) } \\
\hline 0 & 5 \\
\hline 1 & 12 \\
\hline 2 & 4 \\
\hline \multicolumn{2}{|l|}{ Primary tumour (number of patients) } \\
\hline Prostate cancer & 4 \\
\hline Colorectal cancer & 3 \\
\hline Renal cell cancer & 2 \\
\hline Hepatocellular cancer & 2 \\
\hline Sarcoma & 2 \\
\hline Glioblastoma & 1 \\
\hline Lung cancer & 1 \\
\hline Stomach cancer & 1 \\
\hline Pancreatic cancer & 1 \\
\hline Gall bladder cancer & 1 \\
\hline Tonsil cancer & 1 \\
\hline Thyroid (C-cell) cancer & 1 \\
\hline Thrombocythemia & 1 \\
\hline \multicolumn{2}{|l|}{ Previous treatment (number of patients) } \\
\hline Surgery & 15 \\
\hline Chemotherapy & 14 \\
\hline Radiotherapy & 9 \\
\hline Immunotherapy & 4 \\
\hline Time since primary cancer diagnosis (years) & $6.7 \pm 8.8$ \\
\hline Body mass index (kg/m2) & $24.2 \pm 5.6$ \\
\hline Blood pressure $(\mathrm{mmHg})$ & $126 \pm 18 / 82 \pm 11$ \\
\hline Puls rate (Beats/min) & $72 \pm 13$ \\
\hline Rectal temperature $\left({ }^{\circ} \mathrm{C}\right)$ & $36.6 \pm 0.5$ \\
\hline
\end{tabular}

Table 2 Treatment with Helixor ${ }^{\circledast}$ P and dose limiting toxicity (DLT)

\begin{tabular}{llll}
\hline Dose in $\mathrm{mg}$ & $\begin{array}{l}\text { Number of } \\
\text { patients }\end{array}$ & $\begin{array}{l}\text { Treatment } \\
\text { duration (weeks) }\end{array}$ & DLT \\
\hline 200 & 3 & 3 & No \\
400 & 3 & 3 & No \\
700 & 3 & 3 & No \\
1200 & 3 & 3 & No \\
2000 & 3 & 3 & Yes (patient 15) \\
2000 & 3 & 3 & No \\
2000 & 3 & 9 & No \\
\hline
\end{tabular}

respectively (Table 2). There was no drop out. The last patient in the dose group $2000 \mathrm{mg}$ developed a dose limiting toxicity (DLT, allergic reaction with generalized urticaria requiring intravenous antihistamines) during the infusion. According to the protocol, three more patients were treated with this dose for three weeks and tolerated it without DLT. Because no DLT was reached, three more patients were treated with the maximum dose $2000 \mathrm{mg}$ for 9 weeks to evaluate intermediate term safety.

\section{Safety and tolerability}

All patients were evaluated for safety at each visit. In general, Helixor ${ }^{\oplus} \mathrm{P}$ was well tolerated. Tolerability of $2000 \mathrm{mg}$ was not different from $400 \mathrm{mg}$ (Table 3) and none of the infusions was rated as bad or very bad tolerable.

Six serious adverse events (SAE) occurred during the study. All were related to a progress of the disease or other reasons (e.g. hospital admission because of dyspnoe due to pulmonary metastases, change of a bile duct stent due to cholestasis, hospital admission because of dizziness after sudden increase of opiate medication) and not to the study medication. None of the SAE resulted in discontinuation of the study medication. No suspected unexpected serious adverse event (SUSAR) occurred.

One hundred fifty-five adverse events (AE) were documented and classified during the study. No clear dose dependency of the number of AE could be found (Table 4).

Twenty of the $155 \mathrm{AE}$ have been classified as at least possibly related to the study medication, all of them occurred in the dose group $2000 \mathrm{mg}$. These were apart from the allergic reaction in one patient mentioned above: grade 1 fever in 4 patients, weakness the day after infusion $(n=3)$, eosinophilia (up to $19 \%$ in 2 patients), and slight temporary elevation of alanine aminotransferase (ALT) in two patients. Mean levels of ALT, aspartate aminotransferase (AST) and alkalic phosphatase (AP) and neutrophil or lymphocyte counts (Fig. 1) were not changed. In none of the patients with $\mathrm{AE}$, except

Table 3 Patients' rated tolerability of infusion

\begin{tabular}{llllll}
\hline Rating & $200 \mathrm{mg}$ & $400 \mathrm{mg}$ & $700 \mathrm{mg}$ & $1200 \mathrm{mg}^{\mathrm{a}}$ & $2000 \mathrm{mg}^{\mathrm{a}}$ \\
\hline $\begin{array}{l}\text { Number of } \\
\text { infusions rated }\end{array}$ & 9 & 9 & 9 & 9 & 27 \\
Very good & $100 \%$ & $33 \%$ & 0 & $44 \%$ & $33 \%$ \\
Good & 0 & $22 \%$ & $56 \%$ & $33 \%$ & $33 \%$ \\
Moderate & 0 & $44 \%$ & $44 \%$ & 0 & $26 \%$ \\
Bad & 0 & 0 & 0 & 0 & 0 \\
Very bad & 0 & 0 & 0 & 0 & 0
\end{tabular}

${ }^{\mathrm{a}} 2$ missing values 
Table 4 Number of adverse events (AE) in relation to dose administered $(n=155)$

\begin{tabular}{llllllll}
\hline Dose $(\mathrm{mg})$ & 200 & 400 & 700 & 1200 & $2000^{\mathrm{a}}$ & $2000^{\mathrm{b}}$ & $2000^{\mathrm{c}}$ \\
\hline Clinical AE (n) & 2 & 0 & 6 & 3 & 16 & 7 & 1 \\
Laboratory AE (n) & 16 & 16 & 16 & 20 & 14 & 12 & 25 \\
\hline${ }^{\mathrm{a}} n=3$ before DLT; ${ }^{\mathrm{b}} n=3$ after DLT; ${ }^{c} n=3$ for 9 weeks
\end{tabular}

the one with allergic reaction, the study medication was changed.

\section{Clinical observations}

The DLT occurred in a 62-year-old male patient with prostate cancer recurrence. He was obese (Body mass index 31.5), had no history of allergic diseases and had normal ALT levels at baseline. In the night after the first infusion (2000 $\mathrm{mg}$ ) he developed fever and ALT levels increased from 22 to $98 \mathrm{U} / \mathrm{l}$ one week later without concomitant change of gamma glutamyltransferase and alkaline phosphatase. The increase of ALT was regarded as possibly related to the study medication. During the end of the second infusion he developed mild rash and itching at the abdomen, during the third infusion he within 15 min developed generalized urticaria which required injection of $2 \mathrm{mg}$ clemastinfumarate. After $1 \mathrm{~h}$ observation and continuous improving he was sent home. In the nights
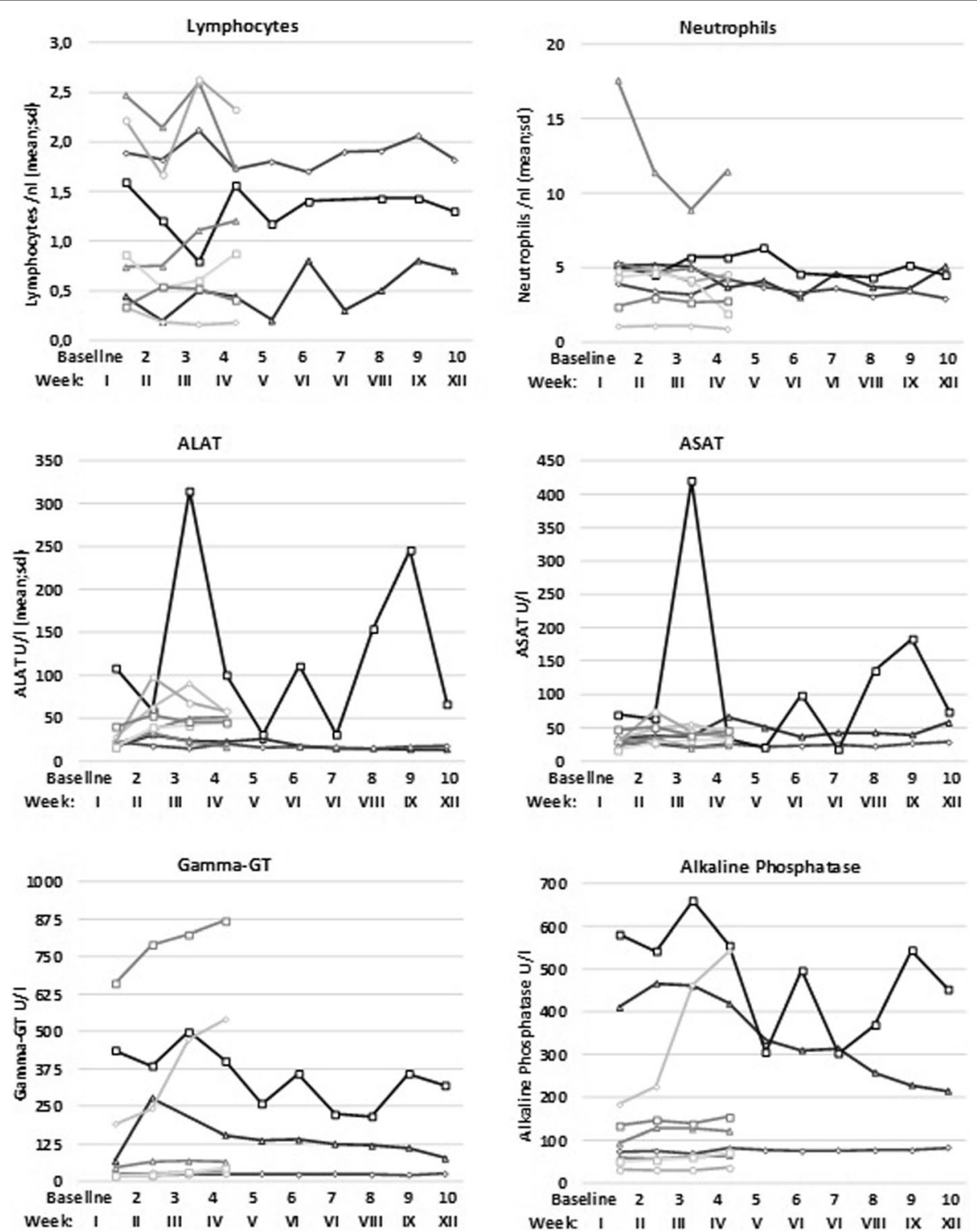

Fig. 1 Course of selected laboratory parameters (neutrophils, lymphocytes, alanine aminotransferase, aspartate aminotransferase, alkaline phosphatase, gamma-glutamyltransferase) of all nine patients ( 6 treated for 3 weeks, 3 treated for 9 weeks) in the $2.000 \mathrm{mg}$ dose-group. Arabic figures indicate the number of visit 
following infusion 2 and 3 he had subfebrile temperature. ALT levels one week after infusion 2 and 3 decreased to 68 and $58 \mathrm{U} / \mathrm{l}$, respectively.

Two patients had unexpected temporary improvement of tumor markers during and after the end of the study. A 50-year-old patient with pancreatic cancer and lung metastases had a reduction of Ca19-9 for 5 weeks during treatment with $700 \mathrm{mg}$ Helixor P (Fig. 2a). One 72year-old patient with metastasized $\mathrm{C}$-cell carcinoma had a stable course of Calcitonin for two months and reported about marked improvement of his pre-existing fatigue during treatment with $2000 \mathrm{mg}$ (Fig. 2b). Both patients were treated off label with the respective dose (700; $2000 \mathrm{mg}$ ) until the tumor marker increased again. Both patients had not received any other anti-tumor treatment the weeks before and during this period.

One 56-year-old patient with peritoneal carcinomatosis and abdominal wall metastases from colorectal cancer has had computed tomography (CT) documented tumor progression with Panitumumab before inclusion into the study. CT controls 3 and 6 months during study and off label treatment with 2000 mg Helixor ${ }^{\oplus}$ P weekly showed stable disease. After 9 months the patient had slow radiological progression and after further slow progression 3 months later (1 year after start of treatment), treatment was changed to intra-tumoral mistletoe injections. The patient is still alive 2.5 years after she entered the study but has slow continuous progression. She

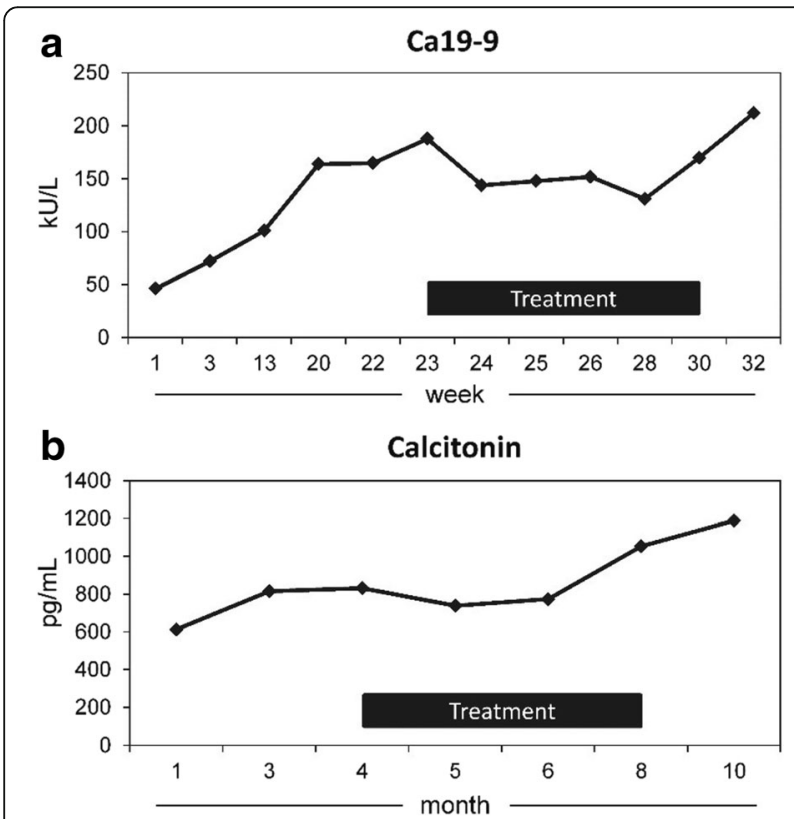

Fig. 2 Tumor markers of a patient with pancreatic cancer (a) and a patient with metastasized C-cell carcinoma (b) before, during and after treatment with 700 mg (a) and 2000 mg (b) Helixor ${ }^{\oplus}$ P. After 3 weeks in the study, treatment was continued off label until tumor markers increased again regularly visited oncologic surgeons and oncologists from the Center for Gastrointestinal Tumors of University Medical Center Freiburg but no other anti-tumor treatment than mistletoe preparations have been given since she entered the study because the tumor was not operable and chemotherapy was refused from her.

\section{Discussion}

This is the first phase I study investigating the MTD of a mistletoe preparation (MP) and the first investigating the intravenous route of application. A DLT was not reached. Infusion of the pre-defined maximum dose of 2000 mg Helixor ${ }^{\circledR}$ P, which contains among others 40,000 ng natural ML III, has a certain risk of allergic reactions and provoking short term $(<12 \mathrm{~h})$ elevated body temperature, but does not seem to have bone marrow or other organ toxicity.

In a pharmacokinetic study a single subcutaneous injection of a mistletoe preparation containing 20,000 ng natural ML I caused fever and fever related symptoms in all probands [8]; up to $10 \mathrm{ng} / \mathrm{kg}$ of recombinant ML had similar side effects [21]. Repetitive subcutaneous injections of ML containing mistletoe products are furthermore known to cause blood eosinophilia [3, 4] and allergic reactions are known as possible side effects (Helixor ${ }^{\circledR}$ investigator's brochure). It seems, therefore, that the spectrum of side effects form ML containing $\mathrm{MP}$ is the same after subcutaneous and intravenous route of application. Administration of higher doses than 2000 mg Helixor ${ }^{\circledR}$ would have offended against the rules of the European Pharmacopoeia, Chapter 2.6.14. "Bacterial Endotoxins", due to an endotoxin level exceeding the regulations. Although the endotoxin-analysis is not reliable, due to a cross-reaction with mistletoe-lectins in the limulus-test [22], no higher doses have been investigated in the study.

In the one patient who had an ALT increase, which was regarded possibly related to the study medication, a direct hepatotoxicity of the IMP is unlikely, because a further increase instead of decrease during continued treatment would have had to be expected. Fever can increase ALT levels [23] and the abnormality can therefore best be explained by fever which was induced by the IMP. None of the patients treated with Helixor ${ }^{\oplus}$ P 2000 mg for 9 weeks showed abnormalities in liver enzyme in comparison to baseline. Also in an observational study in which various concentrations of Helixor ${ }^{\ominus} \mathrm{P}$ where used intravenously, no changes of liver enzymes have been reported [12].

Interestingly, three patients had temporary stable courses of previously deteriorated tumor markers or imaging. Whether this was related to an anticancer effect of the study medication can due to the uncontrolled 
design of our study not be proven. Because no other anticancer therapies have been applied during this time and they had had progression of their disease in the months before entering the study a causal relationship is at least possible. Remission was not assessable as outcome parameter in this phase I study lasting 4-9 weeks for the individual patient only.

Taking together the good safety profile and possible clinical anticancer effects the parenteral application of the IMP deserves future investigations. There are no indications of any new potential side effects related to intravenous infusions of the IMP when compared to the subcutaneous route of application. The data pave the way for a standardized, randomized, placebo-controlled, phase-III-trial testing efficacy of misteltoe, which is urgently needed and essential.

\section{Conclusions}

Weekly infusion of the mistletoe product Helixor ${ }^{\circ} \mathrm{P}$ was tolerated up to a starting dose of $2000 \mathrm{mg}$. In this dose group an increased risk for side effects (allergic reaction, fever) has to be expected. Single patients had unexpected reductions of tumor markers or stable disease.

\section{Abbreviations}

AE: Adverse event; CRF: Case report form; CRO: Contract Research Organisation; CT: Computed tomography; CTCAE: Common toxicity criteria for adverse events; DLT: Dose-limiting toxicity; DMC: Data Monitoring Committee; ECOG (-performance status): Eastern Cooperative Oncology Group; FAS: Full analysis set; IMP: Investigational medicinal product; ML: Mistletoe lectins; MP: Mistletoe preparation; MTD: Maximum tolerable dose; PPS: Per protocol set; RCT: Randomised clinical trial; SAE: Serious adverse event; SAS: Safety analysis set; SOP: Standard operating procedure; SUSAR: Suspected unexpected serious adverse reaction; VaE: Viscum album extract

\section{Acknowledgements}

We thank participants in the study, Dr. C. Schultz (Investigator), Dr. I.U. Fischer (Statistical analysis), B. Diemer (Data management), A. Glockmann (Co-monitoring), Dr. A. Buchwald (Head of laboratory), S. Zeller and O.N. Stuth (Auditing) and Dr. M. Schink (Author of the clinical study report). Furthermore the work of the Data Monitoring Committee (DMC) is acknowledged. Stefan Schmidt (Medical Center - University of Freiburg) and Johannes Gutsch (Witten), the members of the DMC, confirmed in writing their independence from the sponsor with regard to any financial or commercial interest.

\section{Funding}

This work was supported by Helixor Heilmittel GmbH, Rosenfeld, Germany (HELIXOR). It was the only funding source.

\section{Availability of data and materials}

The datasets used and/or analysed during the current study are available from the corresponding author on reasonable request.

\section{Authors' contributions \\ $\mathrm{RH}, \mathrm{DS}$ and WT conceived and designed the study. Responsible for administrative support, collection and assembly of data were WT and SR. RH and WT were accountable for data analysis and interpretation. All authors read and approved the final manuscript.}

\section{Ethics approval and consent to participate}

The study was approved by the German health authorities (BfArM), and registered in the European Union (EudraCTno, 2012-004189-16) and the German Clinical Trials Register Freiburg (DRKS00005028). The positive vote of the responsible ethical committee (University of Freiburg, Germany) was obtained before onset of the study (EK No. 93/13). All participants gave their written informed consent to participate in the study before onset of the study.

\section{Consent for publication}

All patients agreed to publish the study and report individual patient data before onset of the study.

\section{Competing interests}

Dietrich Schlodder, Carola Effertz and Sabine Rieger participated in the study in their capacity as employees of HELIXOR, Wilfried Tröger took part in the study as contract research organisation for HELIXOR. Roman Huber acted as consultant of HELIXOR. Apart from that he declares not to have employments, stock ownerships, further honoraria, paid expert testimonies, patent applications or other supports.

\section{Publisher's Note}

Springer Nature remains neutral with regard to jurisdictional claims in published maps and institutional affiliations.

\section{Author details}

${ }^{1}$ Center for Complementary Medicine, University Medical Center Freiburg, Faculty of Medicine, University of Freiburg, Breisacher Str. 115B, 79106 Freiburg im Breisgau, Germany. ${ }^{2}$ Helixor Heilmittel GmbH, Rosenfeld, Germany. ${ }^{3}$ Clinical Research Dr. Tröger, Freiburg, Germany.

Received: 6 September 2017 Accepted: 12 September 2017

Published online: 18 September 2017

\section{References}

1. Kelter G, Schierholz JM, Fischer IU, Fiebig HH. Cytotoxic activity and absence of tumor growth stimulation of standardized mistletoe extracts in human tumor models in vitro. Anticancer Res. 2007;27(1A):223-33.

2. Elluru SR, Duong van Huyen JP, Delignat S, Kazatchkine MD, Friboulet A, Kaveri SV, Bayry J. Induction of maturation and activation of human dendritic cells: a mechanism underlying the beneficial effect of Viscum album as complimentary therapy in cancer. BMC Cancer. 2008;8:161.

3. Huber R, Rostock M, Goedl R, Lüdtke R, Urech K, Buck S, Klein R. Mistletoe treatment induces GM-CSF- and IL-5 production by PBMC and increases blood granulocyte- and eosinophil counts: a placebo controlled randomized study in healthy subjects. Eur J Med Res. 2005;10(10):411-8.

4. Huber R, Ludtke H, Wieber J, Beckmann C. Safety and effects of two mistletoe preparations on production of Interleukin-6 and other immune parameters - a placebo controlled clinical trial in healthy subjects. BMC Complement Altern Med. 2011, 11(1):116.

5. Horneber MA, Bueschel G, Huber R, Linde K, Rostock M. Mistletoe therapy in oncology. Cochrane Database Syst Rev. 2 edn. 2008:CD003297.

6. Summary of Product Characteristics of the mistletoe preparation Helixor https://www.gelbe-liste.de/produkte/helixor-p 353598/fachinformation

7. Drug guidelines of the German Federal United Commission https://www.gba.de/downloads/83-691-323/AM-RL-I-OTC-2013-06-05.pdf

8. Huber R, Eisenbraun J, Miletzki B, Adler M, Scheer R, Klein R, et al. Pharmacokinetics of natural mistletoe lectins after subcutaneous injection. Eur J Clin Pharmacol. 2010;66(9):889-97.

9. Lyu SY, Park WB. Mistletoe lectin transport by M-cells in follicle-associated epithelium (FAE) and IL-12 secretion in dendritic cells situated below FAE in vitro. Arch Pharm Res. 2010;33(9):1433-41.

10. Büssing, A. Biological and pharmacological properties of Viscum album L., In Mistletoe, The Genus Viscum. Büssing, A. (Ed.). Harwood Academic Publishers, Amsterdam, The Netherlands, pp. 123-182, (2000).

11. Ziska P, Gelbin M, Franz H. Interaction of mistletoe lectins ML I, ML II and ML III with carbohydrates. In: Van Driesche E, Franz H, Beeckmans S, Pfüller U, Kallikorm A, Bog-Hansen TC, editors. Lectins: biology, biochemistry, clinical biochemistry, vol. 8. Hellrup, Denmark: Textop; 1993. p. 10-3.

12. Steele ML, Axtner J, Happe A, Kröz M, Matthes H, Schad F. Safety of Intravenous Application of Mistletoe (Viscum album L.) Preparations in Oncology: An Observational Study. Evid Based Complement Alternat Med. 2014:1-10. doi:10.1155/2014/236310.

13. Büssing $A$, Brückner U, Enser-Weis U, Schnelle M, Schumann A, Schietzel $M$, et al. Modulation of chemotherapy-associated immunosuppression by intravenous 
application of Viscum album L. Extract (Iscador): A randomised phase II study. Eur J Integr Med. 2008;1:44-5.

14. Schink M, Tröger W, Dabidian A, Goyert A, Scheuerecker H, Meyer J, et al. Mistletoe extract reduces the surgical suppression of natural killer cell activity in cancer patients. A randomized phase III trial. Forsch Komplementmed. 2007;14(1):9-17.

15. Büssing A, Bischof M, Hatzmann W, Bartzsch F, Soto-Vera D, Fronk EM, et al. Beeinflussung der Granulozytenfunktion durch einmalige perioperative Mistelextrakt-Infusion. Dtsch Zschr Onkol. 2004;36:148-53.

16. Cazacu M, Oniu T, Lungoci C, Mihailov A, Cipak A, Klinger R, et al. The influence of Isorel on the advanced colorectal cancer. Cancer Biother Radiopharm. 2003;18(1):27-34.

17. Helixor Heilmittel GmbH. Fachinformation Helixor A/-M/-P Deutschland. In.; 2014.

18. Kalden M. Klinische Erfahrungen mit Viscum album bei fortgeschrittenen Tumoren. Erfahrungsheilkunde. 1994;43(6):315-21.

19. Böcher E, Stumpf C, Büssing A, Schietzel M. Prospektive Bewertung der Toxizität hochdosierter Viscum album L.-Infusionen bei Patienten mit progredienten Malignomen. Z Onkol. 1996;28(4):97-106.

20. Storer BE. Design and analysis of phase I clinical trials. Biometrics. 1989; 45(3):925-37.

21. Bergmann L, Aamdal S, Marreaud S, Lacombe D, Herold M, Yamaguchi T, et al. Phase I trial of $r$ viscumin (INN: aviscumine) given subcutaneously in patients with advanced cancer: a study of the European Organisation for Research and Treatment of Cancer (EORTC protocol number 13001). Eur J Cancer. 2008:44(12):1657-62.

22. Scheer R. Beeinflussung des Limulus-Amöbozyten-Lysat-Tests durch MistelLektine. Arzneim-Forsch/Drug Res. 1993;43(III):795-800.

23. Kang KS. Abnormality on liver function test. Pediatr Gastroenterol Hepatol Nutr. 2013;16(4):225-32.

\section{Submit your next manuscript to BioMed Central and we will help you at every step:}

- We accept pre-submission inquiries

- Our selector tool helps you to find the most relevant journal

- We provide round the clock customer support

- Convenient online submission

- Thorough peer review

- Inclusion in PubMed and all major indexing services

- Maximum visibility for your research

Submit your manuscript at www.biomedcentral.com/submit

) Biomed Central 